\title{
DEGRADATION KINETICS AND ORGANIC MATTER REMOVAL CHARACTERISTICS OF ANAEROBIC TREATMENT OF PICKLE CLEANING WASTEWATER
}

\author{
YANG, H. M. ${ }^{1}-$ GU, J. C. ${ }^{2 *}-$ RAN, M. J. ${ }^{1}-$ ZHANG, D. H. ${ }^{1}-$ OU, Y. J. ${ }^{1}$ \\ ${ }^{1}$ Architecture and Civil Engineering, Xihua University, 610039 Chengdu, China \\ e-mail:946259903@qq.com; phone:+86-182-8049-3506 \\ ${ }^{2}$ Food and Biological Engineering, Xihua University, 610039 Chengdu, China \\ *Corresponding author \\ e-mail: gu6471@163.com; phone: +86-136-4809-0701 \\ (Received $15^{\text {th }}$ Mar 2018; accepted 24 $4^{\text {th }}$ May 2018)
}

\begin{abstract}
The method of asynchronous cultivation was used to cultivate surplus sludge in sewage treatment plant under anaerobic environment. The best anaerobic treatment scheme was determined by the single factor and orthogonal experiments, and the degradation kinetics of organic matter in pickle washing wastewater was studied. The characteristics of organic matter removal were studied by Excitation-Emission-Matrix Spectra (3D-EEM) and parallel factor analysis (PARAFAC). The experimental results show that when the influent salinity is $11.98 \mathrm{~g} / \mathrm{L}$, chemical oxygen demand (COD) is $3500 \mathrm{mg} / \mathrm{L}$ and $\mathrm{pH}$ is 7 , the removal rate of COD can reach more than $80 \%$ after anaerobic static $24 \mathrm{~h}$. The order of importance of each factor is: substrate concentration > salinity $>\mathrm{pH}>$ residence time. The kinetics of anaerobic degradation of pickle washing wastewater shows that when the salt content in water samples is $0-30.22 \mathrm{~g} / \mathrm{L}$, the degradation reaction type of inhibitor salt is anti-competitive inhibition. When salt content was $36 \mathrm{~g} / \mathrm{L}$, the inhibition type is a mixed type. 3D-EEM shows that after anaerobic treatment, tryptophan substances in water decreased, humus increased, anaerobic biodegradation transformed most of the macromolecular proteins into humus substances, and the anaerobic ammonification reaction has occurred, which made COD lower while $\mathrm{NH}_{3}-\mathrm{N}$ increased.
\end{abstract}

Keywords: orthogonal experiment, salinity, kinetic study, inhibition type, three-dimensional fluorescence spectroscopy (3D-EEM), parallel factor analysis (PARAFAC), tryptophan, humus

\section{Introduction}

Kimchi wastewater is a kind of typical high salt wastewater, including salt water and cleaning wastewater. It has the characteristics of weak acid and high organic content (Sichuan, 2012). It is difficult to treat, and the quality of water varies greatly with season and the type of pickled vegetables (Li et al., 2012). Kimchi wastewater has great harm. Its rich organic matter, ammonia nitrogen, and phosphorus nutrients can lead to eutrophication of the water body. High salt content will also cause serious salinization of the soil (Sichuan, 2010; Chang et al., 2014). At the same time, because of its weak acidity and high organic content, it can cause odor and breed mosquitoes and flies, Therefore, in order to reduce its impact on the water environment, the pickle wastewater must be concentrated and timely treated (Yang et al., 2017). Therefore, reducing the content of organic pollutants in kimchi wastewater is not only the necessary work to respond to the environmental protection policy but also the necessary work to reduce or even eliminate the threat to the environment and ecological balance (Zhao et al., 2011).

The treatment methods of high salt wastewater mainly include physicochemical method (Wu, 2017; Zhen et al., 2017; Von, 2016), biological method (Li et al., 2013; Du et al., 2014) and biological physicochemical combined technology. The biological 
method has always been a common and efficient treatment method (Sima, 2013) in wastewater treatment. At present, from the domestic and foreign research status of pickle wastewater, there are many studies on pickle salinized wastewater, and most of them are concentrated on the optimization of the bioreactor and the culture of salt eating bacteria. For example, Li et al. (2013) have studied the treatment effect of ASBBR process to the wastewater of pickled vegetable. The results show that the effluent COD can be reduced to $375 \mathrm{mg} / \mathrm{L}$ when the system runs to $79 \mathrm{~d}$, the removal rate is $92.86 \%$. Du et al. (2014) studied the effect of MBR technology on the treatment of salty pickled mustard wastewater. The results showed that the ammonia nitrogen, SS, COD, and phosphate were greatly removed under the intermittent aeration condition. Ali et al. (2011) studied the effect of COD/N ratio and salinity on the performance of the batch reactor. The experiment showed that high salinity inhibited nitrification, and high $\mathrm{COD} / \mathrm{N}$ ratio was beneficial to nitrogen removal (>90\%).

However, little research has been done on pickle cleaning wastewater, and little research has been done on organic composition in pickle wastewater. Compared with saline wastewater, the washing wastewater also has high salinity, and the amount of wastewater is larger, and the water quality fluctuates more. Therefore, this paper takes the pickle cleaning wastewater as the research object, uses the method of domestication of sludge to reduce the inhibitory effect of high salinity on the microorganism, and establishes a stable and efficient anaerobic biological treatment system ( $\mathrm{Yu}, 2009)$. While seeking the best anaerobic treatment conditions and exploring the inhibition mechanism, 3D-EEM and PARAFAC analysis methods are used to further understand the bubble. The feasibility of anaerobic degradation of organic compounds in vegetable cleaning wastewater was verified and provided a theoretical basis for the practical treatment of pickle wastewater. This study not only improved the stability and degradation efficiency of the anaerobic treatment system of pickle wastewater by using the domesticated sludge, but also deeply explored the inhibition mechanism of the salinity on the anaerobic treatment, undertook the task of reducing most of the organic matter, and filled the blank of the organic matter analysis of the pickle wastewater by using 3D-EEM technology.

\section{Experimental materials and methods}

\section{Experimental materials, reagents and instruments}

Wastewater: the pickled vegetable wastewater is taken from pickle plant in Xin Fan Town and be treated by flocculation. The wastewater is light yellow, low turbidity and good transparency. The main index of wastewater is shown in Table 1.

Table 1. Quality indexes of pickle wastewater

\begin{tabular}{c|c}
\hline Project & Content \\
\hline $\mathrm{COD} /(\mathrm{mg} / \mathrm{L})$ & $2000 \sim 3500$ \\
$\mathrm{pH}$ & $6.5 \sim 7.5$ \\
Turbidity & $10 \sim 30$ \\
Salt content $($ calculate by $\mathrm{NaCl}) /(\mathrm{g} / \mathrm{L})$ & $10 \sim 15$ \\
$\mathrm{SS} /(\mathrm{mg} / \mathrm{L})$ & $50 \sim 100$ \\
$\mathrm{NH}_{3}-\mathrm{N} /(\mathrm{mg} / \mathrm{L})$ & $30 \sim 80$ \\
$\mathrm{TP} /(\mathrm{mg} / \mathrm{L})$ & $10 \sim 15$ \\
\hline
\end{tabular}


Anaerobic initial culture sludge: The surplus sludge comes from the sewage treatment plant of hi-tech west district. The concentration of mixed liquor suspended solids (MLSS) is $10.42 \mathrm{~g} / \mathrm{L}$, and the concentration of mixed liquor volatile suspended solids (MLVSS) is $6.42 \mathrm{~g} / \mathrm{L}$.

Experimental reagents: glucose (water), urea, potassium dihydrogen phosphate, two sodium hydroxide, sulfuric acid and silver sulfate, potassium dichromate, mercury sulfate, ammonium ferrous sulfate, potassium sodium tartrate, potassium iodide, mercuric iodide, sodium hydroxide, ammonium chloride, potassium sulfate, ammonium molybdate, potassium antimony tartrate acid, ascorbic acid, potassium dihydrogen phosphate, chloride sodium, silver nitrate, potassium chromate etc..

Experimental instruments: DZKW type electric thermostatic water bath, BS-124-S electronic balance, vacuum suction device, WXJ-III type microwave digestion device, 722s spectrophotometer, JSM280G-18 type portable pressure steam sterilizer.

Experimental device: The anaerobic reactor is a self-made reaction device. The anaerobic bottle adopts a 1.5-L filter bottle as an anaerobic reactor, and the gas is collected by drainage method. The experimental device diagram is shown in Figure 1.

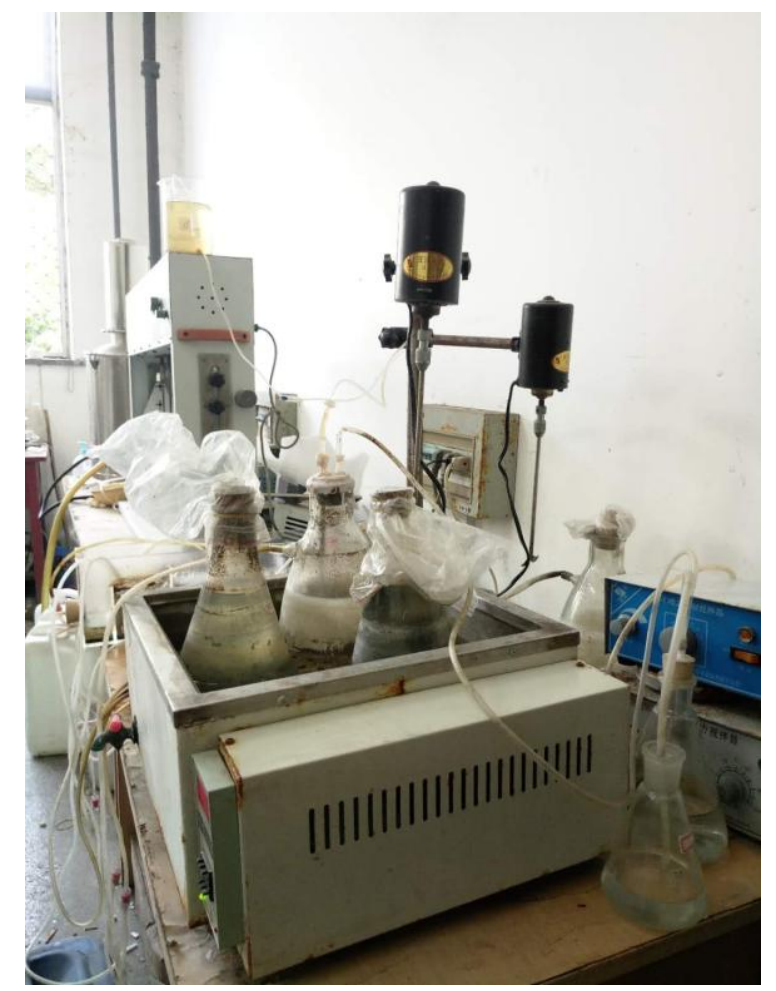

Figure 1. Solid diagram of anaerobic experimental device

\section{Method of experiment and analysis}

\section{Acclimatization of anaerobic activated sludge}

Rinsing the excess sludge with water, and then settle for half an hour later and discard the upper layer of cloudy liquid for so many times. An appropriate amount of sludge was placed in a 1.5-L closed glass reactor, which accounted for about $1 / 3$ of the total volume of the container. Then the culture medium with a nutrient ratio of CODcr:N:P = 200:5:1 (CODcr at about $4000 \mathrm{mg} / \mathrm{L}$, composed of glucose, urea, and two 
potassium hydrogen phosphate) was added for continuous culture. Changing the water every two days, and stirring properly, and controlling the temperature at $37^{\circ} \mathrm{C}$. After a period of time, it was observed that the sludge became darker and darker, and the acidity of the effluent weakened. A large number of bubbles appeared on the surface, indicating that sludge could start domestication. A certain concentration of $\mathrm{NaOH}$ solution was used to adjust the influent $\mathrm{pH}$ to keep it between 6.8 and 7.5. The adaptability of sludge to wastewater water quality is improved by continuous cultivation and acclimatization with flocculating effluent and nutrient solution, and the proportion of flocculated effluent in the influent is gradually increased. COD was measured every 4 days in the domestication period, and COD was measured every 2 days once the acclimation became stable.

\section{Anaerobic experimental process}

After domestication for a month or so, the influent is completely replaced by flocculation effluent, and the anaerobic effluent is basically stable. The best experimental scheme was determined by studying the effects of different influent $\mathrm{pH}$, salinity, substrate concentration, residence time and temperature on COD removal. By changing the salinity of influent, the Monod fitting equation of anaerobic biodegradation kinetics under different salinity conditions was investigated, and the kinetic equation of anti-competitive inhibition was deduced by the steady-state method, which has a further understanding of biodegradation process.

\section{Analysis method of 3D-EEM}

Preparation of water sample: In order to analyze the composition and change characteristics of dissolved organic matter in water samples. First, the original water, anaerobic stable effluent sample and the same batch of water samples were collected in $50 \mathrm{ml}$ plastic sample tube; Then, the water system membrane with a diameter of $50 \mathrm{~mm}$ and $0.45 \mathrm{~m}$ pores was installed in the sand core filter device (Yang et al., 2014). The water samples taken from the previous step were poured into the filter device, the vacuum pump was opened and filtered, and the 50-ml filtrate was collected in the Tetrafluoroethylene bottle, and the water samples were frozen in the icebox at $4{ }^{\circ} \mathrm{C}$ to slow down the metamorphic (Zhu et al., 2014); Finally, the water samples after treatment are sent to the fluorescence spectrophotometer for testing.

The measurement method of water sample: Using deionized water as the blank water sample, the three-dimensional fluorescence characteristics of water samples were scanned by Hitachi F-7000 fluorescence spectrophotometer (Produced by Hitachi hightech company), its parameters were shown in Table 2.

Table 2. Parameter meter of the fluorescence spectrophotometer

\begin{tabular}{c|c}
\hline Project & Parameter setting \\
\hline Excitation wavelength range/nm & $200-600$ \\
Emission wavelength range/nm & $200-600$ \\
Excitation bandwidth/nm & 5 \\
Emission bandwidth/nm & 5 \\
Sampling interval/nm & 5 \\
Scanning speed/nm/min & 30000 \\
PTM Voltage/V & 400 \\
\hline
\end{tabular}


Analysis method of 3D-EEM: The FL Solutions software is used to extract the fluorescence intensity data matrix within the wavelength range, and the matrix is introduced into the drawing software Origin 8.5 to get the three-dimensional contour map of the water sample, at the same time the data is introduced into the Matlab $\mathrm{R} 2014 \mathrm{~b}$ data processing software platform which is pre-installed with the $\mathrm{N}$-way320 and parafacmodeling VER2.0 Toolbox toolkit. After deducting the Raman peak value of the blank water sample, the parallel factor analysis method is used to analyze the parallel factor. Finally, the three-dimensional fluorescence spectrum and the number of parallel factors, the fluorescence peak position and the fluorescence intensity of each parallel component are obtained, and the weakening amplitude is calculated.

\section{Experimental results and discussion}

\section{The degradation of $C O D$ during domestication}

As can be seen from Figure 2, 0-30 d is a period of domestication. During this period, with the increasing of raw water in the entering water, the concentration of chlorine ion is also increasing, and the removal rate of COD is decreasing. The removal rate of COD is reduced to $27.9 \%$ when the entering water is all the raw water; $32-50 \mathrm{~d}$ is a continuous domestication period, and the water entry conditions are consistent. With the prolongation of the culture period, the removal rate of COD increased gradually and reached more than $60 \%$ in the $44 \mathrm{~d}$. At the end of continuous domestication, the removal rate of COD reached more than $65 \%$; 50-68 $\mathrm{d}$ is the stable period of effluent. It can be seen that under the influent water quality, the water quality of the effluent can reach COD below $700 \mathrm{mg} / \mathrm{L}$, and the removal rate of COD is above $70 \%$. Thus, it can be seen that anaerobic sludge acclimation is completed.

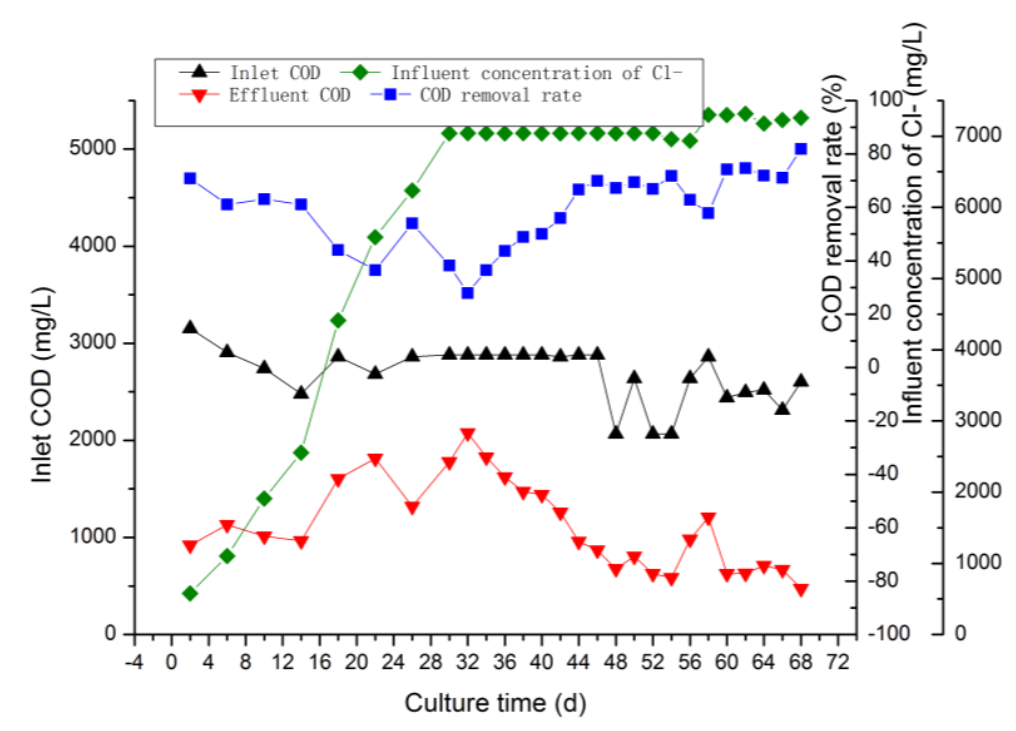

Figure 2. Changes in each index during acclimatization

\section{The effect of $p H$ on the removal of COD}

The reaction temperature was $38{ }^{\circ} \mathrm{C}$, the coagulation effluent was added to the anaerobic device to $1.5 \mathrm{~L}$, and the water was changed every $24 \mathrm{~h}$. The COD degradation 
of the residence time HRT $=24 \mathrm{~h}$ under different $\mathrm{pH}$ influent conditions was investigated, such as Figure 3. The $\mathrm{pH}$ range is 5-9, shaking the reactor manually several times a day, and ensuring that every $\mathrm{pH}$ influent condition stays $4 \mathrm{~d}$ in the anaerobic plant.

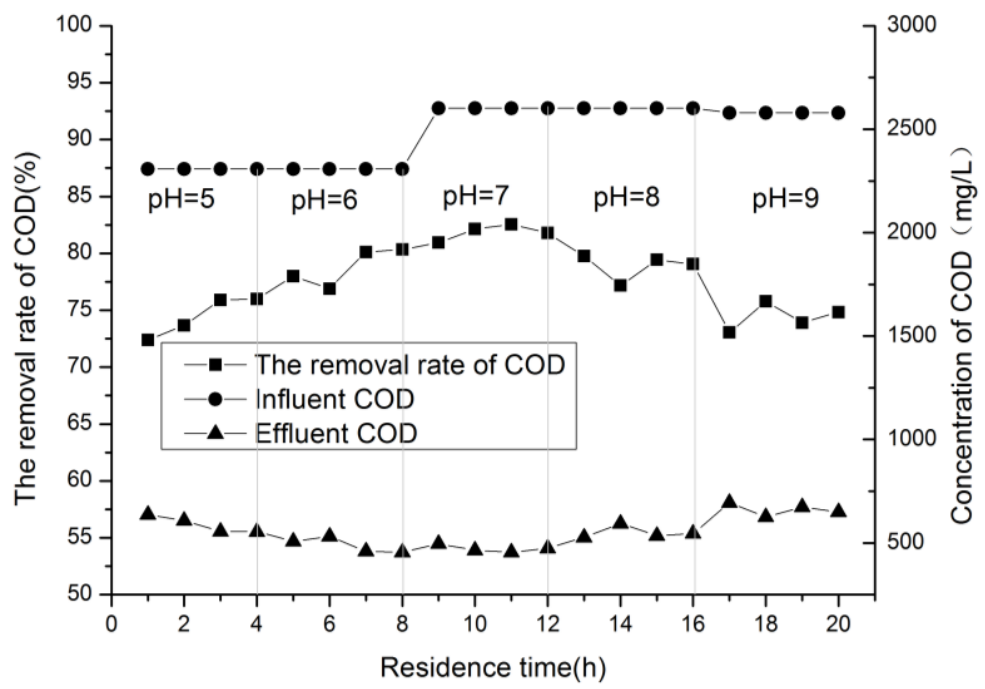

Figure 3. pH effect on COD removal

As can be seen from Figure 3, in the 5-7 range, with the increase of $\mathrm{pH}$ value, the COD removal rate gradually increased, while the $\mathrm{pH}$ value continued to rise, the removal rate began to decline. The best effect was achieved at $\mathrm{pH}=7$, the COD removal rate reached $81.8 \%$, and the COD effluent concentration was $474 \mathrm{mg} / \mathrm{L}$. The degradation effect of COD in the acid environment is better than that of COD in the alkaline environment. This is due to the hydrolysis acidification reaction under acidic conditions, which makes a large number of macromolecule carbon chains in the wastewater break into small molecular carbon chains and decompose organic matter into small molecular substances such as $\mathrm{CO}_{2}, \mathrm{CH}_{4}$ and $\mathrm{H}_{2} \mathrm{O}$ under anaerobic digestion, causing the whole environment to be under the weak acid condition (Hu and Yan, 2009; Liu, 2011), so the best $\mathrm{pH}$ is 6-7.

\section{Effect of substrate concentration on the removal of COD}

The reaction temperature was $38{ }^{\circ} \mathrm{C}$, the coagulation effluent was added to the anaerobic device to $1.5 \mathrm{~L}$, and the water was changed every $24 \mathrm{~h}$. The removal of COD under different COD concentration of influent was investigated, as shown in Figure 4. COD changes in the range of $1000-5500 \mathrm{mg} / \mathrm{L}$, gently swaying several times a day and ensuring a stable operation of each concentration for 4 days.

As can be seen from Figure 4, when HRT $=24 \mathrm{~h}$, in the range of 1000-3500 mg/L COD increased with the concentration of substrate removal rate increased gradually, but when the concentration continues to rise, the removal rate began to decline, so the best effect in COD is $3500 \mathrm{mg} / \mathrm{L}$, the removal rate of COD reached $85.6 \%$, the effluent COD concentration is $466 \mathrm{mg} / \mathrm{L}$. The low substrate concentration will cause the low organic load of activated sludge and increase the operating cost, while too high substrate concentration will cause the excessive organic load to cause the excessive acid 
production of sludge to make the reactor acidosis and affect the effect of effluent. Therefore, it is necessary to control the COD concentration at the appropriate level (Liu, 2011).

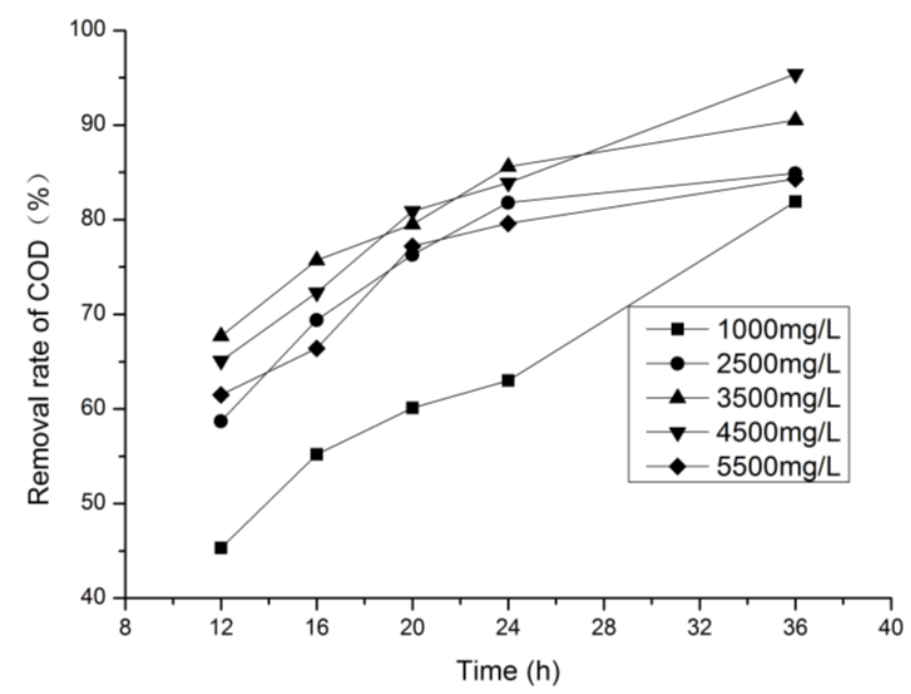

Figure 4. The effect of substrate concentration on the removal of COD

\section{Influence of residence time on the removal efficiency of COD}

The reaction temperature was $38{ }^{\circ} \mathrm{C}$, the coagulation effluent was added to the anaerobic device to $1.5 \mathrm{~L}$, and the water was changed every $24 \mathrm{~h}$. The influent COD concentration is $2602 \mathrm{mg} / \mathrm{L}, \mathrm{pH}=7$ and salinity is $11.98 \mathrm{~g} / \mathrm{L}$, The removal of COD under different residence time was investigated, as shown in Figure 5.

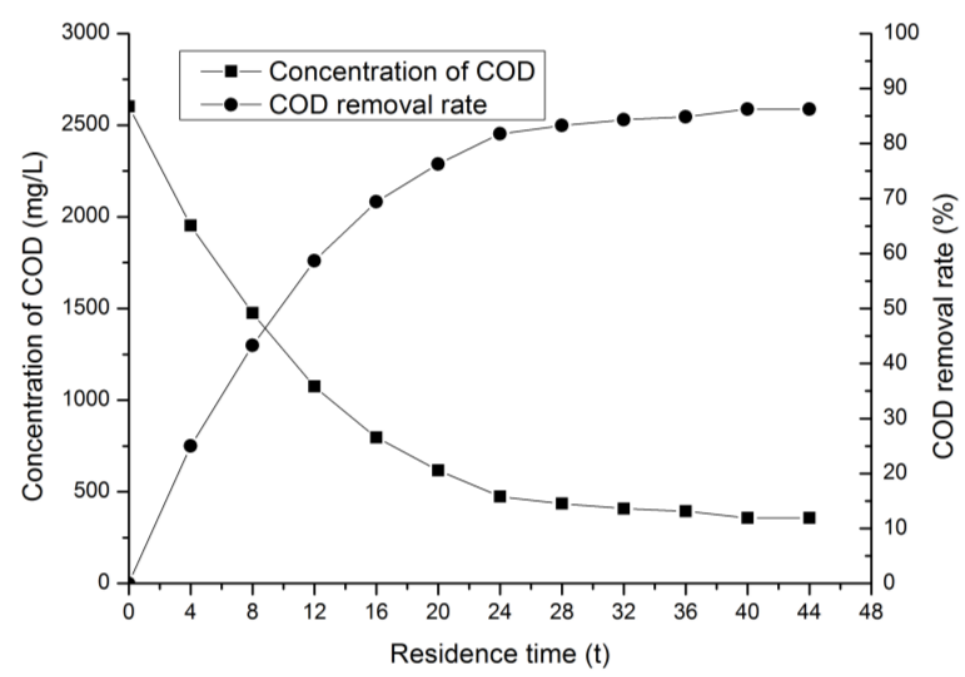

Figure 5. The effect of residence time on the removal of COD

As can be seen from Figure 5, with the prolongation of residence time, the effluent concentration of COD decreases gradually, and the COD removal rate increases gradually, and tends to balance at HRT $=24 \mathrm{~h}$. Therefore, the best residence time is 
$24 \mathrm{~h}$, the COD removal rate reaches $81.8 \%$, and COD effluent concentration is $474 \mathrm{mg} / \mathrm{L}$.

Study on the effect of salinity on the anaerobic degradation of pickle cleaning wastewater and its kinetics

The reaction temperature was $38{ }^{\circ} \mathrm{C}$, the coagulation effluent was added to the anaerobic device to $1.5 \mathrm{~L}$, and the water was changed every $24 \mathrm{~h}$. The removal of COD under the different salt concentration of influent was investigated, as shown in Figure 6. Salt changes in the range of 0-36 g/L, gently swaying several times a day and ensuring a stable operation of each concentration for 4 days.

From Figure 6 we can see that the removal rate of pickle cleaning wastewater increases with the increase of HRT, and it can be seen that at the same HRT, the removal rate of COD decreases with the increase of salt concentration. When the salinity was maintained at $11.98 \mathrm{~g} / \mathrm{L}$, the removal rate is $81.8 \%$; when the salinity was reduced to $0 \mathrm{~g} / \mathrm{L}$ and $6.5 \mathrm{~g} / \mathrm{L}$, the removal rate of COD increased to $90.3 \%, 82.6 \%$; when the salinity was increased to $17.93 \mathrm{~g} / \mathrm{L}, 24.16 \mathrm{~g} / \mathrm{L}, 30.22 \mathrm{~g} / \mathrm{L}, 36 \mathrm{~g} / \mathrm{L}$, the removal rate decreased to $79.3 \%, 68.9 \%, 67.4 \%, 64.1 \%$ respectively. It can be seen that the acclimated anaerobic sludge can achieve good results in the treatment of pickles cleaning wastewater in the $0-24 \mathrm{~g} / \mathrm{L}$ salinity range.

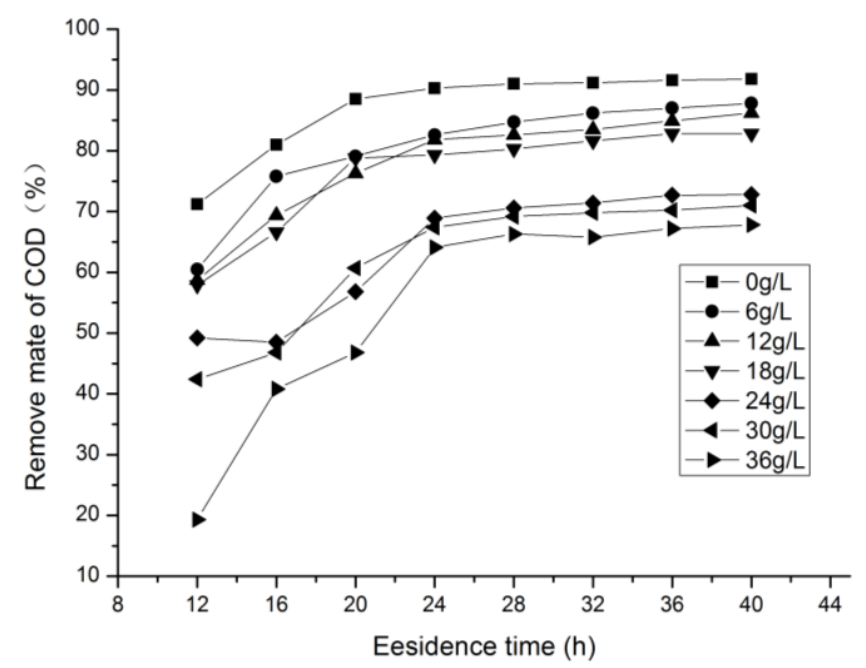

Figure 6. Effect of different salinity at different residence time on COD removal

As can be seen from Figure 6, different amount of salt in the anaerobic digestion process has an inhibition on microbial metabolism at different levels, the relationship between the specific growth rate and the matrix concentration is no longer consistent with the Monod relationship. Therefore, it is necessary to modify the kinetic formula of Monod specific growth rate according to the characteristics of wastewater and inhibitor.

The anaerobic biological removal rate of the usual matrix is described by the Monod equation (Eq. 1; Liu, 2011):

$$
V=\frac{V \max S}{K s+S}
$$


The Monod fitting equation for the kinetics of anaerobic biodegradation of organic matter under the conditions of salinity is shown in Figure 7a-g. The Monod fitting equation for the kinetics of anaerobic biodegradation of organic compounds under different salinity conditions in Figure 7 is shown in Table 3.

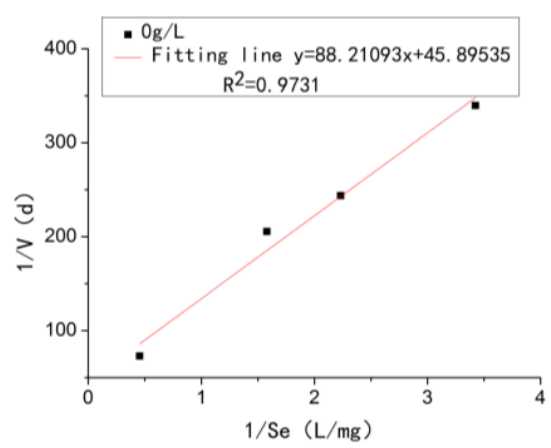

a

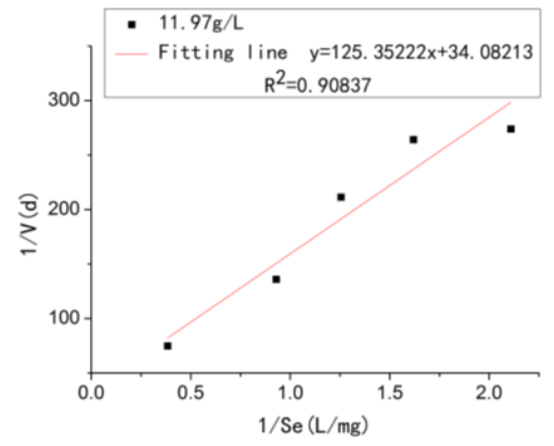

c

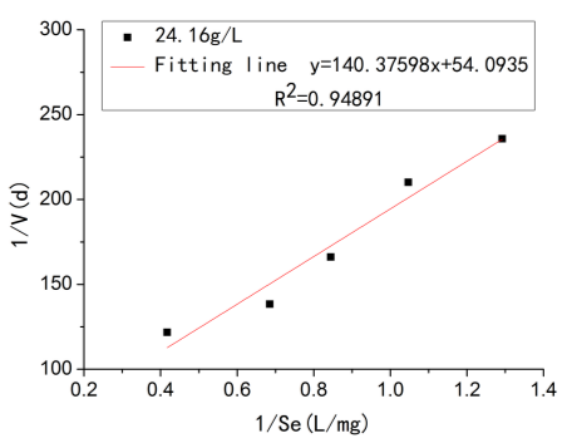

e

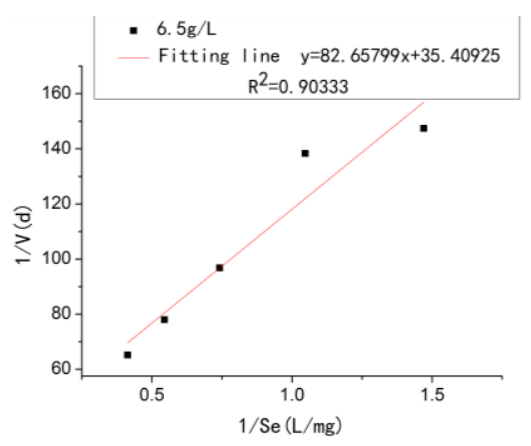

b

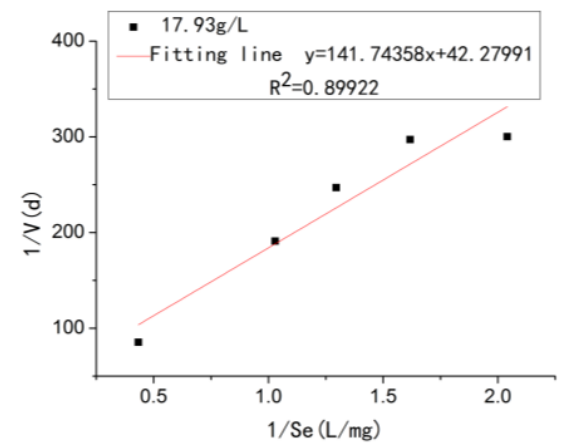

d

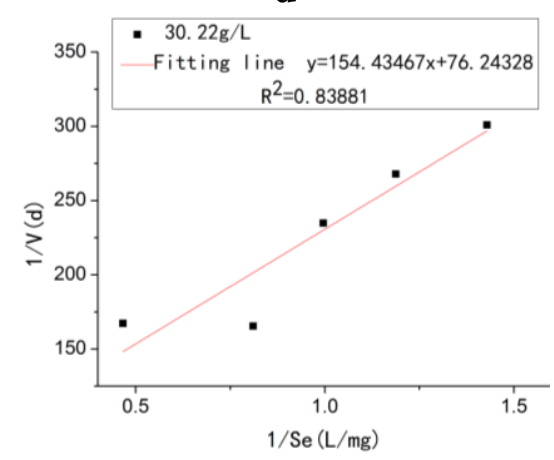

$\mathbf{f}$

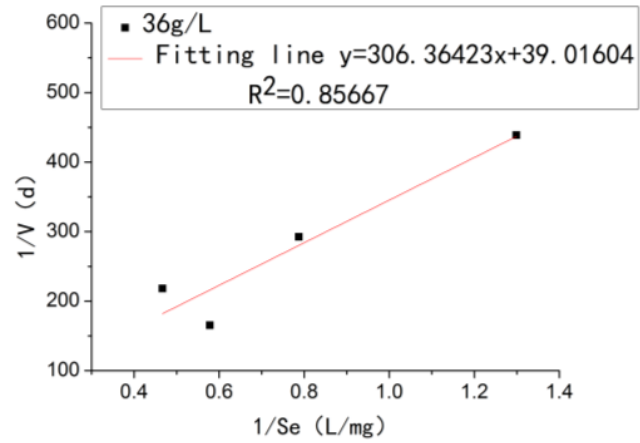

$\mathbf{g}$

Figure 7. a. $0 \mathrm{~g} / \mathrm{L}$ fitting line; $\boldsymbol{b} .6 .5 \mathrm{~g} / \mathrm{L}$ fitting line; $\boldsymbol{c .} 11.97 \mathrm{~g} / \mathrm{L}$ fitting line; $\mathbf{d} .17 .93 \mathrm{~g} / \mathrm{L}$ fitting line; e. $24.16 \mathrm{~g} / \mathrm{L}$ fitting line; $f .30 .22 \mathrm{~g} / \mathrm{L}$ fitting line; $\mathrm{g} .36 \mathrm{~g} / \mathrm{L}$ fitting line 
Table 3. Experimental results of anaerobic biodegradation reaction of acclimated sludge from $11.98 \mathrm{~g} / \mathrm{L}$ wastewater

\begin{tabular}{c|c|c|c|c|c|c|c|c}
\hline $\begin{array}{c}\text { Serial } \\
\text { number }\end{array}$ & $\begin{array}{c}\text { Salinity } \\
(\mathrm{g} / \mathrm{L})\end{array}$ & Fitting equation & $\mathrm{R}^{2}$ & $\begin{array}{c}\text { MLSS } \\
(\mathrm{mg} / \mathrm{L})\end{array}$ & $\begin{array}{c}\mathrm{K}^{\text {or } \mathrm{V}_{\max }} \\
\left(\mathrm{d}^{-1}\right)\end{array}$ & $\mathrm{K}^{*}$ & $\begin{array}{c}\mathrm{K}_{\mathrm{S}} \\
(\mathrm{mg} / \mathrm{L})\end{array}$ & $\mathrm{K}_{\mathrm{S}}{ }^{*}$ \\
\hline 1 & 0 & $\mathrm{y}=88.21093 \mathrm{x}+45.89535$ & 0.9731 & 9510 & 0.0218 & 0.743 & 1.923 & 0.52 \\
2 & 6.5 & $\mathrm{y}=82.65799 \mathrm{x}+35.40925$ & 0.90333 & 9510 & 0.0282 & 0.96 & 2.33 & 0.63 \\
3 & 11.98 & $\mathrm{y}=125.35222 \mathrm{x}+34.08213$ & 0.90837 & 9510 & 0.02934 & & 3.68 & \\
4 & 17.93 & $\mathrm{y}=141.74358 \mathrm{x}+42.27991$ & 0.89922 & 9510 & 0.0237 & 0.81 & 3.359 & 0.91 \\
5 & 24.16 & $\mathrm{y}=140.37598 \mathrm{x}+54.0935$ & 0.94891 & 9510 & 0.01849 & 0.63 & 2.596 & 0.705 \\
6 & 30.22 & $\mathrm{y}=154.43467 \mathrm{x}+76.24328$ & 0.83881 & 9510 & 0.01312 & 0.447 & 2.026 & 0.55 \\
7 & 36 & $\mathrm{y}=306.36423 \mathrm{x}+39.01604$ & 0.85667 & 9510 & 0.0256 & 0.087 & 7.85 & 2.13 \\
\hline
\end{tabular}

Comparing the value of $\mathrm{K}, \mathrm{K}_{0}, \mathrm{Ks}$, and $\mathrm{K}_{\mathrm{S} 0}$, according to the following formula A-D in Table 4 can infer the type of inhibition.

Table 4. Inhibition type table

\begin{tabular}{c|c|c}
\hline Formula number & Inhibition type & Inhibition condition \\
\hline $\mathrm{A}$ & Competitive & $\left.K=K_{0}, K_{s}\right\rangle K_{S 0}$ and $\left.K^{*}=1.0, K_{s}^{*}\right\rangle 1.0$ \\
\hline $\mathrm{B}$ & Non-competitive & $K\left\langle K_{0}, K_{s}=K_{S 0}\right.$ and $K^{*}\left\langle 1.0, K_{s}^{*}=1.0\right.$ \\
\hline $\mathrm{C}$ & Anti-competitive & $K\left\langle K_{0}, K_{s}\left\langle K_{S 0}\right.\right.$ and $K^{*}\left\langle 1.0, K_{s}^{*}\langle 1.0\right.$ \\
\hline $\mathrm{D}$ & Mixed & $K\left\langle K_{0}, K_{s}\right\rangle K_{S 0}$ and $K^{*}\left\langle 1.0, K_{s}^{*}\right\rangle 1.0$ \\
\hline
\end{tabular}

Note: $\mathrm{V}, \mathrm{V}_{\max }-$ to the removal rate and the maximum ratio of removal $\left(\mathrm{d}^{-1}\right) ; \mathrm{S}, \mathrm{S}, \mathrm{S}_{\mathrm{e}}-$ influent, reactor and water matrix concentration $(\mathrm{mg} / \mathrm{L}) ; \mathrm{X}-$ microbial concentration $(\mathrm{mg} / \mathrm{L}) ; \mathrm{t}$ - eaction time $(\mathrm{h}) ; \mathrm{K}^{*}$ and $\mathrm{K}_{\mathrm{s}}^{*}$ - inhibition constants; $\mathrm{K}$ - The maximum ratio of substrate removal in the absence of inhibitor $\left(\mathrm{d}^{-1}\right) ; \mathrm{K}_{\mathrm{S} 0}-$ The saturation constant in the absence of a suppressing substance; $\mathrm{K}_{\mathrm{I}}-$ The dissociation equilibrium constant of an inhibitor and an enzyme (microorganism) complex, also known as the inhibitor constant

According to the inhibition types determined by the above methods, the inhibition mechanism can be analyzed. Further, the inhibition kinetic constant $\mathrm{K}_{\mathrm{I}}$ of substrate anaerobic biodegradation can be obtained by dynamic steady-state treatment.

It can be seen from Table 3 and Figure $7 a-g$ that the substrate $\mathrm{V}_{\max }$ of the organic compounds in the anaerobic degradation wastewater is lower than the acclimated salt concentration when the content of salt is below $11.98 \mathrm{~g} / \mathrm{L}$ and higher than $11.98 \mathrm{~g} / \mathrm{L}$. This shows that the change of salt content in the wastewater has a certain inhibitory effect on the anaerobic microorganism which has been adapted to the high salt concentration. At the same time, it can be seen from Table 4 that when the concentration of salt is $0-30.22 \mathrm{~g} / \mathrm{L}, \mathrm{K}^{*}<1$ and $\mathrm{Ks}^{*}<1$, it is known that the type of degradation reaction is anti- competitive inhibition, that is, the sodium chloride in wastewater cannot combine with the enzyme directly, $\mathrm{NaCl}$ can only combine with 
enzyme-substrate complex to form an intermediate complex, enzyme-substrateinhibitor.

$1 / \mathrm{V}_{\max }$ is used to make a straight line of salt concentration $\mathrm{I}$, its longitudinal intercept is $1 / \mathrm{V}_{\max }$, the slope is $1 / \mathrm{V}_{\max } \mathrm{K}_{\mathrm{I}}$, the fitting line equation is $\mathrm{y}=1.10392 \mathrm{x}+24.75291$, and $\mathrm{KI}=22423 \mathrm{mg} / \mathrm{L}$ can be calculated. The greater the $\mathrm{K}_{\mathrm{I}}$ value, the less inhibition of anaerobic degradation of organic matter. Anti-competitive inhibition kinetic fitting curve sees Figure 8.

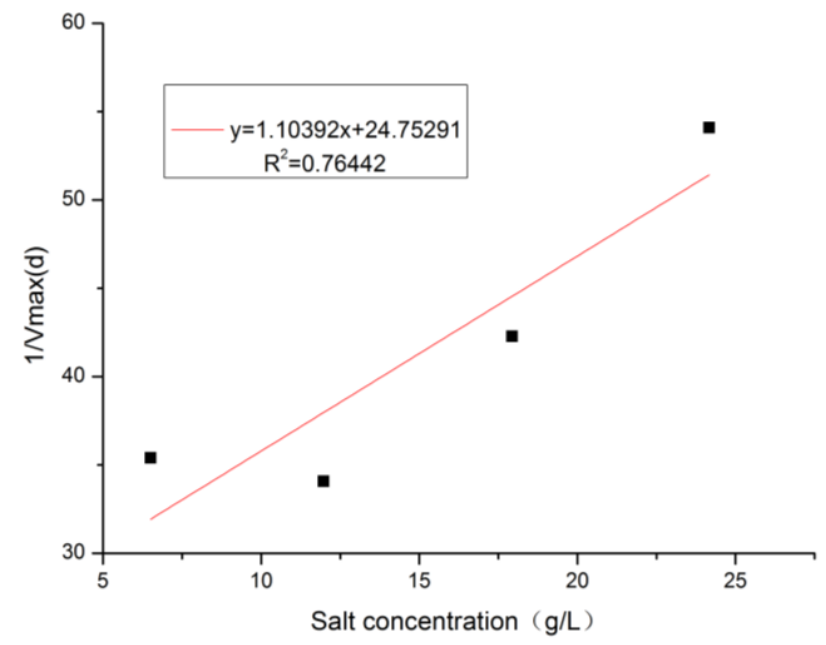

Figure 8. Anti-competitive inhibition kinetic curve fitting curve

Therefore, when the salt content in the water sample is $\leqq 30.22 \mathrm{~g} / \mathrm{L}$, the anticompetitive inhibition kinetic equation of the salt concentration to the anaerobic COD degradation reaction is as follows $(E q .2)$ :

$$
V=\frac{V_{\max } S /\left(1+\frac{i}{K_{I}}\right)}{K_{s} /\left(1+\frac{i}{K_{I}}\right)+S}=\frac{V_{\max } S}{K_{s}+S /\left(1+\frac{i}{K_{I}}\right)}=\frac{0.02934 S}{3.68\left[1+\frac{i}{22423}\right]}
$$

When the salt content is $36 \mathrm{~g} / \mathrm{L}, \mathrm{K}^{*}<1$ and $\mathrm{Ks}^{*}>1$, the type of $\mathrm{NaCl}$ 's inhibition of wastewater is mixed type, the reaction process is relatively complex.

\section{Optimization of anaerobic activated sludge for COD degradation}

\section{Formulation of the orthogonal experiment}

Through the above single factor experiments, 4 factors were determined in this experiment, the concentration of A: the substrate, $\mathrm{B}$ : salinity, $\mathrm{C}: \mathrm{pH}$, and $\mathrm{D}$ : residence time. Each factor was selected in three levels. The level table of the experimental factors was shown in the lower Table 5, and the orthogonal experiment was carried out by the L9 $\left(3^{4}\right)$ orthogonal table. 
The result and analysis of the orthogonal experiment

The results of the orthogonal experiment are shown in Table 6. From the result of Table 6, the order of importance of each factor is $\mathrm{B}>\mathrm{C}>\mathrm{A}>\mathrm{D}$. The main influence factor in the experimental range is $\mathrm{B}$ substrate concentration, followed by $\mathrm{C}$ salinity, and then $\mathrm{CpH}$, factor $\mathrm{D}$ residence time is the smallest. It is determined that the best scheme of anaerobic biodegradation to the pickle cleaning wastewater is A2B2C1D1, that is, when COD concentration is $2500 \mathrm{mg} / \mathrm{L}$, the salt content is $6 \mathrm{~g} / \mathrm{L}, \mathrm{pH}$ is 7 , residence time is $20 \mathrm{~h}$, the effluent is the best.

Table 5. Experimental factor level table for anaerobic treatment

\begin{tabular}{c|c|c|c|c}
\hline Level & \multicolumn{3}{|c}{ Factor } \\
\hline $\mathbf{K}$ & $\mathbf{p H}$ & Substrate concentration $(\mathbf{m g} / \mathbf{L})$ & Salinity $(\mathbf{g} / \mathbf{L})$ & Residence time (h) \\
\hline 1 & 6 & 1500 & 6 & 20 \\
2 & 7 & 2500 & 12 & 24 \\
3 & 8 & 3500 & 18 & 28 \\
\hline
\end{tabular}

Table 6. Orthogonal experimental results of anaerobic treatment

\begin{tabular}{c|c|c|c|c|c}
\hline Serial number & A & B & C & D & COD removal rate /\% \\
\hline 1 & 1 & 1 & 1 & 1 & 73 \\
2 & 1 & 2 & 2 & 2 & 70.15 \\
3 & 1 & 3 & 3 & 3 & 66.84 \\
4 & 2 & 1 & 2 & 3 & 56 \\
5 & 2 & 2 & 3 & 1 & 78.48 \\
6 & 2 & 3 & 1 & 2 & 78.57 \\
7 & 3 & 1 & 3 & 2 & 49.87 \\
8 & 3 & 2 & 1 & 3 & 77.92 \\
9 & 3 & 3 & 2 & 1 & 62.19 \\
$\mathrm{~K} 1 \mathrm{j} / 3$ & 70 & 57.34 & 76.5 & 71.22 & \\
$\mathrm{~K} 2 \mathrm{j} / 3$ & 71.02 & 75.52 & 62.78 & 66.2 & \\
$\mathrm{~K} 3 \mathrm{j} / 3$ & 63.33 & 69.2 & 65.06 & 66.92 & A2B2C1D1 \\
$\mathrm{Rj}$ & 6.67 & 18.18 & 13.72 & 4.3 & \\
Optimal scheme & $\mathrm{A} 2$ & $\mathrm{~B} 2$ & $\mathrm{C} 1$ & $\mathrm{D} 1$ & \\
\cline { 2 - 5 } The importance of each factor & \multicolumn{5}{|c}{$\mathrm{B}>\mathrm{C}>\mathrm{A}>\mathrm{D}$} \\
\hline
\end{tabular}

Note: Kij - the index value of the test results at the level I of the $\mathrm{j}$ factor; the difference in the $\mathrm{Rj}$ - the $\mathrm{j}$ factor

\section{Removal of fluorescent organic matter}

\section{Measurement results of 3D-EEM}

The three-dimensional fluorescence spectrum and contour map of water intake and anaerobic effluent were shown in Figures 9 and 10. Before and after treatment, COD decreased from $2068 \mathrm{mg} / \mathrm{L}$ to $584 \mathrm{mg} / \mathrm{L}$, and the removal rate was $71.8 \%$. $\mathrm{NH}_{3}-\mathrm{N}$ increased from $52.8 \mathrm{mg} / \mathrm{L}$ to $135.3 \mathrm{mg} / \mathrm{L}$ and increased by $156.3 \%$. The spectrogram of the contour clearly expresses the excitation of the peak intensity of the spectral peak 
intensity of the influent and the effluent, and the position and relative intensity of the emission wavelength. You can see from Figure 9, the water has a strong peak excitation/emission band at $270 \sim 295 \mathrm{~nm} / 340 \sim 360 \mathrm{~nm}$; can be seen from Figure 10, the anaerobic effluent has 4 fluorescence peak excitation / emission bands are located at $270 \sim 295 \mathrm{~nm} / 340 \sim 360 \mathrm{~nm}, 245 \sim 285 \mathrm{~nm} / 420 \sim 450 \mathrm{~nm}, 295 \sim 310 \mathrm{~nm} / 420 \sim$ $450 \mathrm{~nm} .345 \sim 370 \mathrm{~nm} / 420 \sim 450 \mathrm{~nm}$. Because of the large changes in the front and back-fluorescence peaks, it can be found that the species of soluble organic matter in water has changed greatly before and after the anaerobic treatment. At the same time, it can be seen from the contour map that the spectral map overlaps to a certain extent.

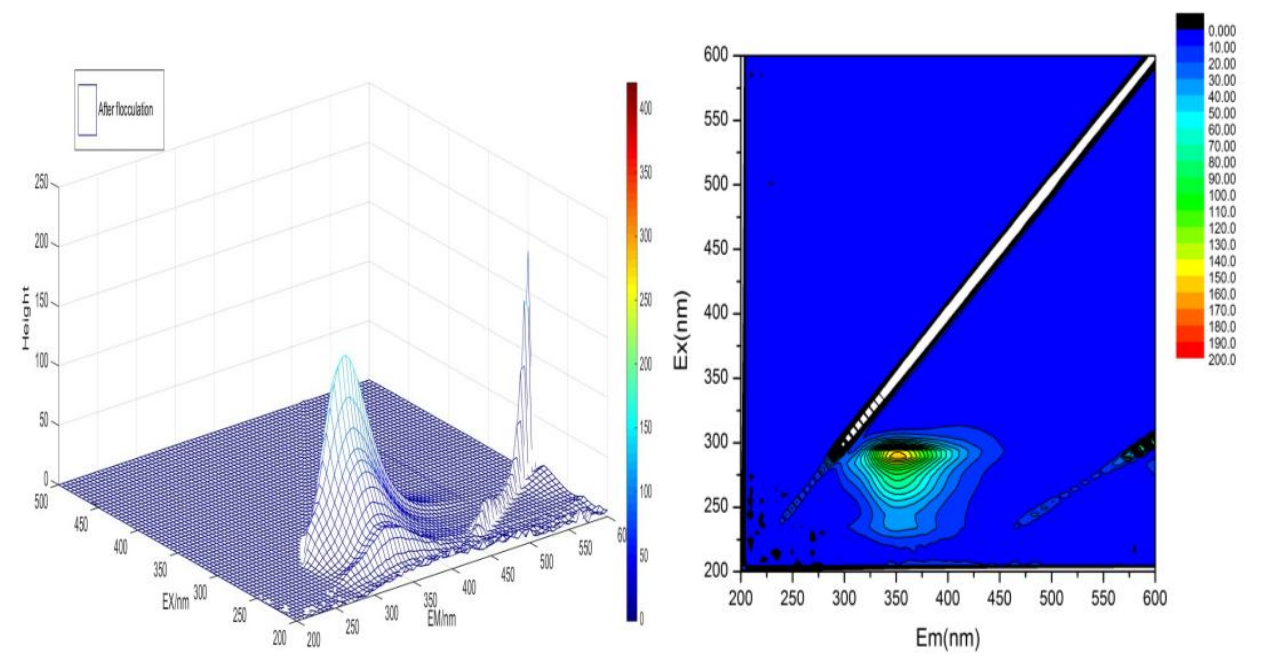

Figure 9. Influent fluorescence spectrum and contour map
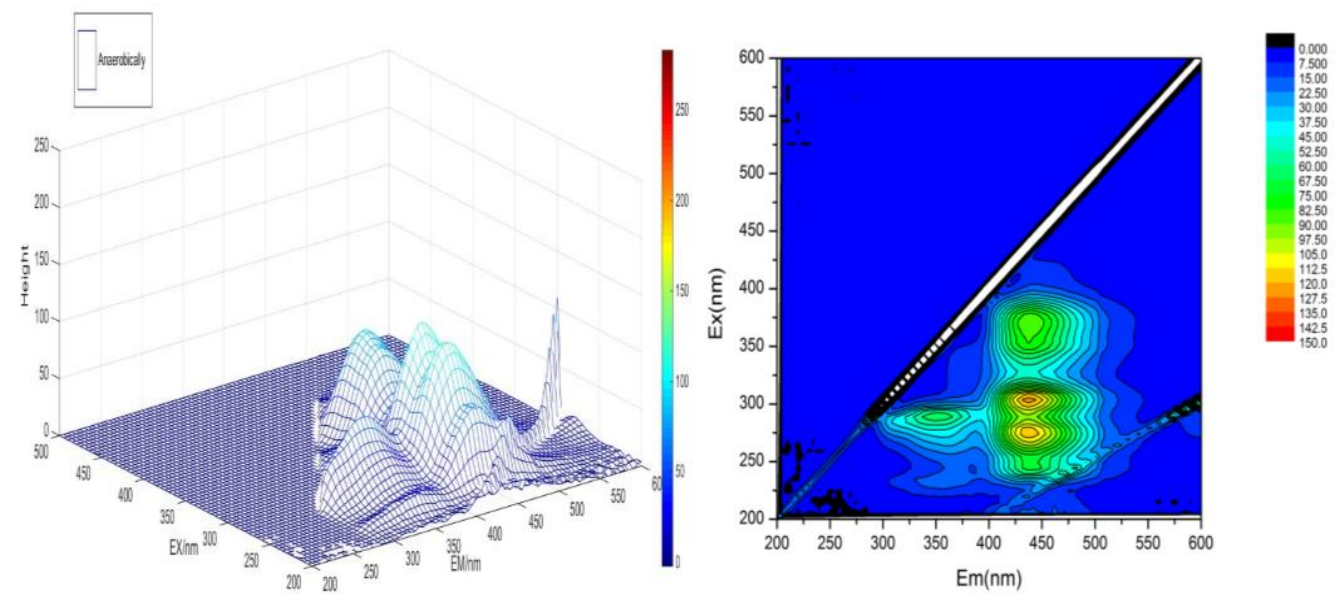

Figure 10. Fluorescence spectra and contour maps of anaerobic effluent

\section{Results of parallel factor analysis}

For the same batch of 5 samples, the original data matrix $(5 * 82 * 82)$ was measured by PARAFAC parallel factor analysis. 3 parallel factors in the water sample were obtained by the parallel factor analysis model, and the core consistency map is shown in Figure 11. Parallel factor decision rule: when the kernel consistency is greater than or 
equal to $80 \%$ or in the vicinity, show that this factor is reliable and that $50-80 \%$ is not stable, then, $<50 \%$ for the problem. The choice of factor number is to select the maximum number of factors before the kernel conformance is rapidly falling (Ma, 2014).

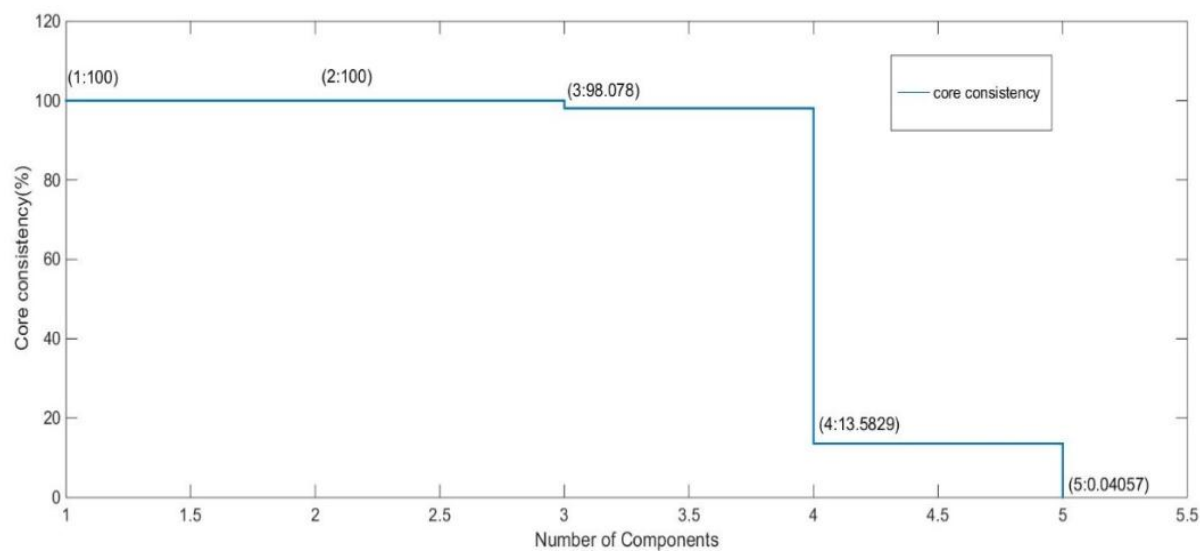

Figure 11. Core consistency diagram

The 3-factor excitation and emission spectral profiles obtained by using the parallel factor model are shown in Figure 12.
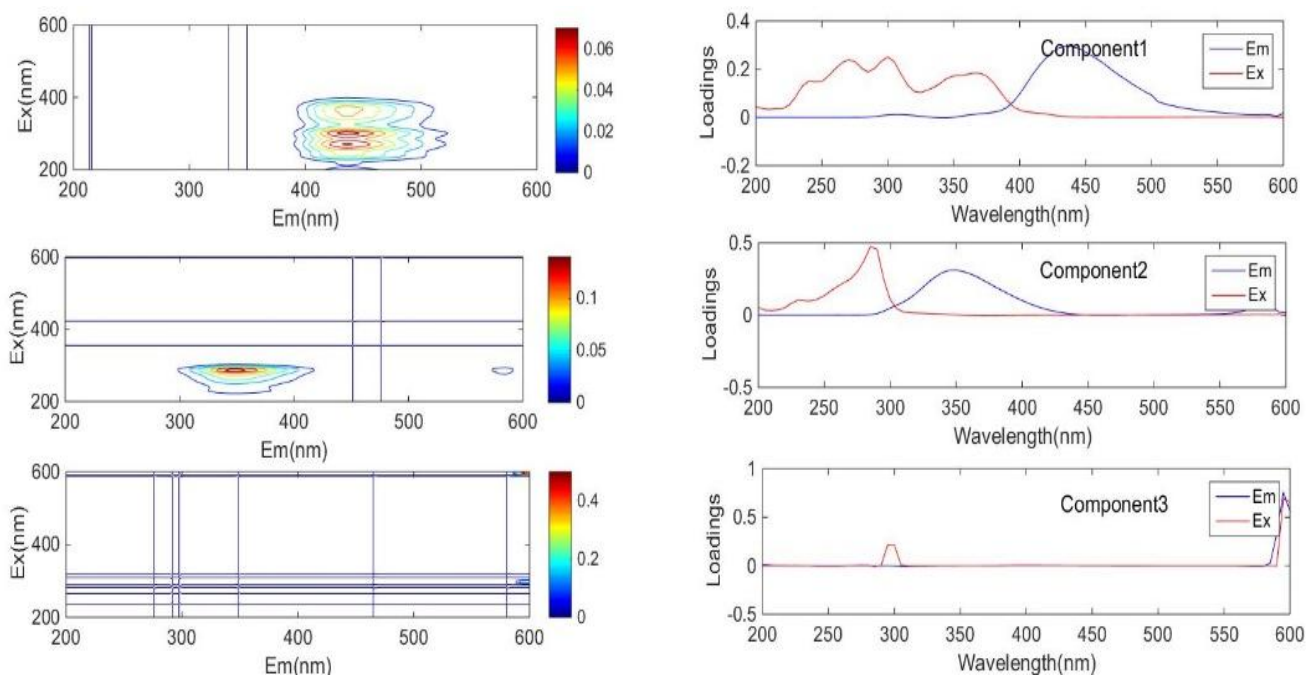

Figure 12. Parallel factor excitation and emission spectrogram

As can be seen from Figure 12, factor 1 has 4 optimal excitation wavelength, were $250 \mathrm{~nm}, 270 \mathrm{~nm}, 300 \mathrm{~nm}, 360 \mathrm{~nm}$, optimal emission wavelength is $435 \mathrm{~nm}$, respectively characterizing that UVA humus produced by terrestrial plants or soil organic matter, the unknown humus produced by microbiological processes, UVA humic substances produced by terrestrial plants, endogenous microorganism processes, and UVC humic substances produced by terrestrial plants or soil organic matter, belonging to visible fulvic acid. Therefore, factor 1 indicates a kind of humus-like substance (Zhu et al., 2014; Ma, 2014; Hao et al., 2007; Liu et al., 2012). The optimal excitation and emission wavelength of factor 2 is $285 / 350 \mathrm{~nm}$, characterizing that highly excited luminescent 
tryptophan produced by terrestrial plants, endogenous generation and microbial processes, which is amino acids that are free or bound to proteins and the fluorescence characteristics are similar to those of free tryptophan, indicating a complete protein or less degraded peptide (Hao et al., 2007; Liu et al., 2012). While factor 3 did not find the full fluorescence peak and the best emission wavelength. The inference is that it should be caused by scattering and cannot indicate organic matter in water. From Figure 9 and 10 can be seen that after anaerobic treatment factor 2 fluorescence peaks decreased, that is, the fluorescence peak intensity of tryptophan is reduced by $58.7 \%$. While factor 1 fluorescence peaks increased, the fluorescence peak intensity of the humus is increased by 11.5 times. Protein reduced and humic substances in water increased after anaerobic treatment, we can indicate that anaerobic biodegradation has converted most of the macromolecular proteins into humus, and the anaerobic ammonification reaction has been taken, which made COD lower while $\mathrm{NH}_{3}-\mathrm{N}$ increased.

\section{Conclusion and prospect}

(1) The concentration and impact of salinity will inhibit the anaerobic microorganism's degradation ability. In this study, the adaptability of anaerobic microorganisms to high salt wastewater was improved by acclimation of anaerobic sludge. After domestication, the removal rate of COD increased from $27.9 \%$ to over $70 \%$. The single factor optimization results showed that the removal rate of COD could be raised to more than $80 \%$ again under the condition of $\mathrm{pH}=7$ and the residence time for $24 \mathrm{~h}$. It is indicated that the water quality is the most significant factor affecting the anaerobic effect. Try to ensure that the influent water quality is stable at COD concentration of $2500 \mathrm{mg} / \mathrm{L}$, the salinity of $6 \mathrm{~g} / \mathrm{L}$ and $\mathrm{pH}$ of 7 , so as to achieve the best effect of effluent. Therefore, the anaerobic treatment system in this study is feasible for treating pickle cleaning wastewater.

(2) According to the results of 3D-EEM research, there are a lot of tryptophan (protein) in the pickle cleaning wastewater. The anaerobic biodegradation can convert most of the large molecular protein into humus, and the anaerobic ammonification reaction has occurred, which made COD lower while $\mathrm{NH}_{3}-\mathrm{N}$ increased. Therefore, anaerobic treatment in this study has a significant contribution to the removal of organic matter from Pickles wastewater.

(3) Follow up studies can focus on the following aspects: First of all, biological or physicochemical methods should be combined for further treatment of anaerobic effluent to ensure effluent quality. Secondly, in the future research, we need to further optimize the methods of cultivation and domestication of anaerobic sludge, further shorten the cycle of acclimation and put into operation at an early date. Finally, it is necessary to expand the scale of the anaerobic reactor and investigate the treatment effect in the actual engineering application.

\section{REFERENCES}

[1] Ali, R. P., Luqman, C. A., Fakhru'l, R et al. (2011): Evaluation of membrane bioreactor for hypersaline oily wastewater treatment. - Process Safety and Environmental Protection 90(1): 45-55. 
[2] Chang, M. Q., Zhao, X. J., Liu, J. N., Jian, L. (2014): The environmental problems and Countermeasures in Sichuan pickle industry. - Environmental Science and Management 39(9): 167-170.

[3] Du, J., He, Q., Chai, H. X., Zhao, J. (2014): Intermittent aeration compound MBR treatment of salty pickled mustard wastewater treatment. - China Water Supply and Drainage 30(1): 70-72.

[4] Hu, P., Yan, Q. (2009): A preliminary study of the anaerobic degradation of biogas by cyanobacteria and sludge stick. - Environmental benevolent process 3(3): 559-563.

[5] Hao, R. X., Cao, K. X., Deng, Y. W. (2007): Characterization of dissolved organic pollutants in sewage by three-dimensional fluorescence spectrometry. - Laboratory Analysis (10): 41-44.

[6] Li, X. P., Wei, S. S., Han, Y., Zhou, J., Chen, L., Yang, Z. (2013): ASBBR ultra high salt pickle wastewater. - Journal of Environmental Engineering 7(12): 4697-4702.

[7] Li, Y. Q., Ran, D., Yang, P. (2012): On the wastewater discharge of Sichuan pickled vegetable industry. - Environmental Science and Management 2: 19-21.

[8] Liu, J. G. (2011): Study on the treatment of pickled mustard wastewater by coagulation anaerobicelectrode SBBR method. - Southwestern University, Chongqing. DOI: 10.7666/d.y1881708.

[9] Liu, X. H., Zhang, Y. L., Yin, Y., Zhi, Q. (2012): When the three-dimensional fluorescence spectra and parallel factor analysis in the research of CDOM application.Chinese Journal of Oceanology and Limnology 62(3): 133-145.

[10] Ma, T. (2014): Changes in fluorescent organic compounds in water and sewage treatment. - Zhejiang University of Technology, Zhejiang.

[11] Sichuan, P. A. D. (2012): Three years to double the Sichuan kimchi industry new steps. Sichuan Agricultural Science and Technology 3: 6.

[12] Sichuan, S. P. S. S. (2010): Pickles. - Sichuan Provincial Bureau of Quality and Technical Supervision, DB51/T 1069-2010.

[13] Sima, W. P. (2013): Study on the synergistic treatment of nitrogen and phosphorus removal from organic wastewater with high salt, high nitrogen and phosphorus pickled water and urban sewage. - Chongqing University, Chongqing.

[14] Von, S. (2016): Micro electrolysis - Fenton oxidation for the removal of high salt wastewater COD research. - Environmental Science and Management 41(10): 103-106.

[15] Wu, Z. S. (2017): Application of membrane concentration and multi effect evaporation in the treatment of high concentration salt wastewater. - Chinese Chlor Alkali (4): 36-38.

[16] Yang, H. M., Gu, J. C., Zhang, D. H., Ou, Y. J., Ran, M. J. (2017): PAC and PAM composite flocculant in the treatment of pickled cabbage wastewater. - Civil Construction and Environmental Engineering 39(4): 95-101.

[17] Yang, S., Zhou, Q. X., Hua, T. (2014): Characterization of dissolved organic matter in municipal wastewater A/DAT-IAT system and ecological safety. - Environmental Science 35(2): 633-642.

[18] Yu, G. (2009): Stability regulation and treatment of high salt aerobic granular sludge and treatment of pickled mustard wastewater. - Chongqing Jiaotong University, Chongqing.

[19] Zhao, F., Pu, B., Liu, X. Y., Chen, A. J. (2011): PAFC and PAM compound flocculant for the treatment of kimchi wastewater. - Food and Fermentation Industry 37(12): 81-83.

[20] Zhen, S. L., Li, Q., Ma, W. C., Sang, H. J., Zhang, M. (2017): Application of Fenton oxidation technology in the treatment of high salinity COD wastewater. - Environmental Sanitation Engineering 25(2): 59-62.

[21] Zhu, G., Yin, J., Zhang, P., Wang, X., Fan, G., Hua, B., Ren, B., Zheng, H., Deng, B. (2014): DOM removal by flocculation process: Fluorescence excitation-emission matrix spectroscopy (EEMs) characterization. - Desalination 346: 38-45. 